\title{
Commentary on criminology at Cambridge
}

\author{
Helen Smith
}

The decision to return to student life occurred while I was working as a registrar on a general psychiatry training scheme. I had already determined that forensic psychiatry was for me, and one of the reasons for this was my fascination with the complex interactions between psychiatry and the law. A chance conversation with a lawyer led me to the Institute of Criminology at Cambridge University. Part of the Faculty of Law, the Institute offers a Master of Philosophy Degree in Criminology as a one year, full-time, taught course.

Criminology seemed to offer a unique opportunity to build a broad base of knowledge, with courses in such diverse subjects as The Criminal Justice System, Feminist Perspectives on Criminology, Sentencing Theory, Police Powers, and others that would not have been easily accessible during my psychiatric training.

Having decided that this was the course for me, I set about the task of applying for a place. I approached an academic at the Institute a year before starting the course to discuss my intended application and the course in general. Places are given without interview, making it important to have some direct contact with a member of the department to help them put a face to a name when the time comes to apply.

Entry to the course requires the student to become a full-time member of the University, and also a member of a College. These simple requirements oblige the student to both live in or around Cambridge, and to have no other employment. Terms at Cambridge are short compared to other universities, but the majority of assessed work is set over the holiday period. The possibility of locum work during this time seems attractive, but the volume of course work precludes this.

I eventually applied in December of 1994 and received my offer of a place in Spring 1995. The course in Cambridge is expensive. Course fees for the year were just over $£ 2400$ (1995-96), which is comparable with other courses, but there is an additional College fee of just over $£ 1600$. Accommodation in Cambridge is not included in these fees and does not come cheap! College accommodation is the most economical option, but is still over $£ 70$ per week for what is euphemistically described as a one bed-roomed flat, but is in reality little more than a bedsit with a sliding wall partitioning off the bed.

I was unable to get much help with funding. The only contribution I had was of $£ 200$ from a pharmaceutical company. There are grants associated with the Institute and with my college, Trinity Hall, but I was not successful in my applications for these. Funds obtained by frugal saving and many locum nights on-call paved the way for my year at Cambridge.

The course started on the 2 October with the traditional 'freshers week'. This was most peculiar, having last been a fresher some 10 years before. The majority of people on postgraduate courses appear to have come straight from first degrees. There were a handful of people of similar age to myself and a further small group who were significantly older and either retired or thinking of a career change.

In all around 48 people started the degree, coming from a wide variety of backgrounds. Represented among these was one other psychiatrist, lawyers, sociologists, psychologists and geography students. The group was multinational, with students from the USA, Canada, Australia, New Zealand, Greece and South Africa. This wide variety of academic backgrounds and cultures led to many interesting discussions and points of view.

The course is assessed on the basis of four essays from a variety of options offered during the year, a research methods exercise relating to the compulsory research methods course and a short thesis. Students are expected to attend four options courses (normally two in the Michaelmas term and two in the Lent term) on which they wish to write their essays, and are welcome to attend as many other options as they wish. The compulsory methods course covered both qualitative and quantitative research methods and ran through both the Michaelmas and Lent terms.

In general the course was well taught, and I have no complaints about the standard of the modules I chose to take. I deliberately avoided modules allied to psychiatry, as I felt that it was better to choose the options that I would otherwise not have the chance to study. I chose 


\section{EDUCATION}

options associated with the law and the prison system in order to broaden my basic knowledge of the systems most associated with work in my professional life. Each module consisted of one seminar each week, attended by 15-20 students and preceded by considerable background reading.

I was not alone in feeling that the course lacked the formal tutorial system normally associated with Cambridge. Although assigned a tutor, an ad hoc system of meetings exists, and seemed to be confined to discussion of the intended short thesis rather than for wider discussion of other aspects of the course. It seemed at times as if the course had become a series of lectures, and that it was not willing to provide students with an adequate amount of personal time from the tutors.

\section{Post-mortem}

How do I evaluate the experience now? Being a full-time student on any degree course gives one the opportunity to move away from clinical commitments and indulge oneself solely in academic pursuit. I was able to learn about aspects of the legal system, prison system and crime and deviancy that I would otherwise not have had time to do. I was able to spend time reading and exploring topics without other commitments interfering. The research module gave an insight into qualitative research methodology which would have been difficult to attain otherwise in my training.
The negative side of the course is the expense, not only in terms of the fees, but also that of lost income for the duration of the course. This course can only really be practicable for those normally resident outside Cambridge if they are single, have a very understanding partner or a family that is able to transplant itself with them. I felt, particularly as a self-funder, that the course would have benefited from more individual attention rather than its current structure of large group teaching.

The department reminded me of school days with its register taking at seminars and dispersal of core assessed work. Assessed work was handed out at the end of each term to assure attendance at course lectures.

All in all the experience was a positive one. I believe that developing a broader base of knowledge will allow more proficient practice in my chosen speciality and that this additional qualification will hold me in good stead for future job applications!

\section{Acknowledgement}

I thank Martin Humphreys for his help and advice with the manuscript.

Helen Smith, Research Registrar in Forensic Psychiatry, Reaside Clinic, Bristol Road South. Rubery, Birmingham B45 9BE 